\title{
Why Moral Norms Cannot be Reduced to Facts: On a Trilemma in Derivations of Moral "Ought" from "Is"2
}

\section{Two approaches to the problem of justification in ethics}

One may endeavour to realize the (arguably) main task of ethical reflection - that of justifying moral norms - in two different ways, viz. either by embedding moral norms in normative statements (that is: the less specific moral norms in the more general ones) or in factual statements. The first approach encounters the notorious difficulty which consists in that in creating a "logical chain" of moral norms (in which every preceding - higher-level - norm is a direct basis for the derivation of the next one - a lower-level, more specific norm) we reach the most fundamental ("highest-level") moral norm(s) which cannot be derived from any other norm. This most fundamental moral norm(s) cannot therefore be justified in a deductive way: it (they) must be accepted as "self-evident". Accordingly, the first approach may provide only a partial justification of moral norms: it may justify only secondary norms but not the most fundamental ones (on the plausible assumption that accepting a norm as "self-evident" cannot count as its justification). Arguably, this feature of the normative justification of moral norms is one of the main reasons why philosophers have devoted so much attention to the problem of the possibility of deriving moral norms from factual statements (that is, deriving moral "ought" from "is"). If an attempt at such

ORCID number: 0000-0002-4860-0836. E-mail: zaluskiwojciech@gmail.com

2 The following article was prepared as part of the project realized by The Foundation of Copernicus Center for Interdisciplinary Studies "Humanities in Dialogue", financed by the Ministry of Science and Higher Education within the program "Dialog" (no. of the contract: 0239/DLG/2018/10).

3 The above passage clearly shows that in my considerations I take into account only what may be called "strong" justification of moral norms, i.e. the deductive one. There are two reasons for that. Firstly, this is the kind of justification that is relevant in the context of the analysis of the possibility of the derivation of moral "ought" from "is". Secondly, and more importantly, this is the least controversial and the strongest (as opposed, e.g. to the inductive), and - for that reason - also most often encountered form of ethical justification: one can plausibly argue that most attempts at a justification of a moral norm by another moral norm take the form of a more or less explicit deduction (the deduction is less explicit when it is not clear whether a given more specific norm is an instance of a more general one, e.g. whether the prohibition of abortion is an instance of the prohibition of killing a human being). In the case of a less explicit deduction the analysis of facts is, of course, of crucial importance (e.g. quaestio facti of whether a foetus can be considered a human being). A highly problematic question (which will be answered in the negative in this paper) is whether the premises of the (ethically justificatory) deduction can be factual statements "standing alone" (i.e. not jointly with normative statements). 
a derivation proved to be successful, it would provide a complete, not partial, justification, that is, the justification would also embrace the most fundamental moral norm or norms. However, as will be argued in this paper, the very idea of such a justification seems to be ill-conceived, since any attempt to derive moral "ought" from "is" with a justificatory goal (i.e., with the goal of justifying a moral norm or norms), if successful in its "derivation" part, would face a certain trilemma in its "justification" part. After presenting the trilemma and conducting a "case study" (an analysis of Searle's famous derivation of "ought" from "is") to illustrate it, I will also devote some attention (in section 5) to the trilemma's broader implications for the problem of justification in ethics.

\section{Factual statements: value-laden and value-free}

Prior to constructing the trilemma the term "factual statements" has to be defined with precision. Depending on one's metaphysical outlook, one may either assert that there are only value-free factual statements or also value-laden ones. The latter statements are factual in the sense that they say how things are, that is, they are indeed "is-statements". But they are based on the assumption that values are part of the described reality, that they are somehow "inscribed" in it (e.g. that "goodness" or "badness" are sui generis - non-natural and/or supervenient - features of states of affairs or actions). The justification of moral norms by deriving them from value-laden factual statements is therefore based on the assumption that values are located "on the side" of facts. It therefore rejects the existence of the dichotomy between facts and values: it assumes that at least some facts have by themselves, i.e. irrespectively of the emotional reactions of observers, an axiological character. Accordingly, on this view, a complete description of a given fact should take into account its axiological dimension (if the fact does have such a dimension, because this view assumes, of course, that facts can also be value-neutral).

Depending on how the relation between the statements " $x$ is good (bad)" and " $x$ ought (not) to be" is understood, two variants of this view can be distinguished. On the assumption that " $x$ is good" means " $x$ ought to be (done)" (and, analogously, that " $x$ is bad" means " $x$ ought not to be (done)"), factual statements of this kind seem to provide (given the definitional connections) grounds for deriving moral norms. A more complicated situation arises if one denies the existence of the definitional link between the terms "good' and "ought": in this case one faces the problem of deriving "ought" from "good", which seems no less problematic than that of deriving "ought" from "is" (or, arguably, is simply a variant of the latter problem). But even if we assume the first variant, and thereby affirm the existence of the definitional link between "good" and "ought", the derivation of "ought" from the value-laden factual statements proves to be, upon closer inspection, impossible.

The first obstacle to such a derivation (which also applies to the second variant) has an epistemic character and is related to the question of how to distinguish true descriptions of value-laden facts from the false ones: some people may consider a given fact to be "good", that is, one which "ought to be (done)", while other people may consider the same fact as "bad", that is, one which "ought not to be (done)". Accordingly, the problem of distinguishing justified from unjustified moral norms - the problem to which the derivation of "ought" from "is" was supposed to provide a solution - reappears at

Let me recall that it is a moot point whether the transition from the predicates "good"/"bad" to normative statements is permissible. 
the level of the axiological evaluation of facts. In other words, there arises the problem of the justification of the fundamental moral evaluative judgment: it must be assumed to be self-evident. Thus, the ethical justification would still be partial/incomplete. The second obstacle (which concerns only the first variant) is as follows: if "good" means "ought to be" or "ought to be done", then the value-laden factual statement can be regarded as a deontic statement; we cannot therefore speak about any derivation, let alone about derivation with a justificatory goal.

But one may query whether yet another type of value-laden factual statements should not be distinguished, viz. those containing the so-called "thick" ethical concepts (such as courageous, chaste, generous, proud), which are sometimes considered to directly entail evaluative and also (if "good" is assumed to mean "ought to be (done)") deontic sentences. However, it can be plausibly argued that the statements containing "thick" ethical concepts are purely descriptive, and therefore no evaluation can be derived from them. To put it more precisely, in order to ascertain whether, for instance, a generous person or a chaste person is also morally good, one needs to make a separate act of evaluation; the moral qualification (as good or wrong) is therefore not analytically entailed by these "thick" concepts; their moral evaluation depends on the moral system we assume. In other words, whether a given feature (described by "thick" concepts) is morally good is by no means obvious. For instance, the "monkish virtues" (as called by David Hume) of penance, self-denial, humility or silence were much appreciated by religious thinkers and ridiculed by Hume (and many other thinkers). This remark applies to all features; even an apparently (morally) uncontroversial virtue of justice can be criticized as, say, being inferior to mercy. Thus, in order to state whether a given feature/disposition is morally good, we must beforehand prove or assume a moral system within which this feature is regarded as morally good. Furthermore, even if we could point at features/dispositions which are doubtlessly (morally) good, one could argue, following Kant, that they are only conditionally good, because even they can be put to improper use $\mathrm{e}^{5}$.

In the remainder of my analysis, I am going to focus on the second understanding of factual statements, and treat them as value-free, that is, devoid of an evaluative component. It is assumed, on this understanding, that there is a dichotomy between facts, on the one hand, and values and norms, on the other. I am going to argue that the attempt to derive moral "ought-statements" from factual statements thus understood is exposed to a trilemma.

\section{A trilemma of the attempts to derive "moral ought" from "is"}

Let us assume, firstly, that the goal of an attempt to derive moral "ought" (that is, a moral norm $M_{1}$ imposing an obligation) from "is" (that is, from a (value-free) factual statement $F_{1}$ about human actions) is to provide a justification of a moral "ought"; and secondly, that the attempt is successful, that is, someone did manage to derive $M_{1}$ from $F_{1}$ according to any logically correct method. Then the question (alternative) arises whether a similar

\footnotetext{
This somewhat quick analysis of the thorny issue of thick concepts and extensively commented on in the literature would require a development. This would, however, be beyond the scope of this paper. As for the (vast) literature on thick concepts, see, e.g. S. Blackburn, Through Thick and Thin, "Proceedings of the Aristotelian Society" 1992/66, pp. 285-299; S. Burton, "Thick”Concepts Revisited, "Analysis” 1992/52, pp. 28-32; J. Dancy, In Defense of Thick Concepts, "Midwest Studies in Philosophy" 1995/20, pp. 263-279; H. Putnam, The Collapse of the Fact/Value Dichotomy and Other Essays, Cambridge (Mass.) 2002. Putnam, e.g. defends a different view on thick concepts than that presented above, claiming that it is not possible to separate their descriptive and evaluative components.
} 
derivation (based on the same method) can be made from all possible factual statements $F_{i}$ about human actions or only from some specific ones (only $F_{l}$ or perhaps also some others, but not all $F_{i}$ ). The answer to this question points at the existence of the following trilemma:

1) If the first part of the alternative were true, that is, if from a factual statement about any human action a moral norm (qualifying this action as "ought", that is, as obligatory) could be derived, then a moral system built in this way would be rather peculiar, because it would consider each human action of which a factual statement can be made as morally obligatory. It would therefore "justify" a large number of implausible moral norms ${ }^{6}$.

2) If the second part of the alternative were to hold, that is, if the derivation could be made only from some factual statements, then one would need a criterion for identifying those facts from which moral norms can be derived. If this criterion were moral, one could not derive it from facts without falling into infinite regress. Thus, there would be at least one, and moreover especially important, norm which could not be derived from facts.

3) And if this criterion were non-moral (based, e.g. on some features of language of those factual statements which are supposed to entail normative statements), then the justification would still not be provided, since the non-moral criterion cannot count as relevant for distinguishing between facts which "give rise" to moral norms and those which do not.

\section{A case study: John Searle's derivation of "ought" from "is"}

\subsection{An analysis of Searle's derivation: an illustration of the trilemma}

Thus far, the trilemma has been presented in an abstract manner. To see more clearly how it manifests itself, let us examine probably the most famous attempt at deriving "ought" from "is", viz. the one proposed by John Searle 7 . Searle presented the following reasoning from "is-statements" (1.-4.) to an "ought-statement" (5.), each of the "is-statements", with the exception of the first one, ensuing from the preceding one:

1. Jones uttered the words "I hereby promise to pay you, Smith, five dollars."

2. Jones promised to pay Smith five dollars.

3. Jones placed himself under (undertook) an obligation to pay Smith five dollars.

4. Jones is under an obligation to pay Smith five dollars.

5. Jones ought to pay Smith five dollars.

Let us assume, as most commentators of Searle's argument do, that it is formally valid, that is: each successive statement of this series is entailed by the preceding one,

\footnotetext{
In the above formula, the trilemma refers to obligations (deontic sentences following the pattern "it is (morally) required that..."). But its scope is broader: it can be reformulated (generalized), mutatis mutandis, to other than "ought" forms of normative/deontic sentences, viz. to: prohibitions ("ought not" - "it is prohibited/impermissible"), permissions ("it is permissible that..."), omissions ("it is omissible that...") or, optional deontic sentences ("it is both permissible and omissible that..."). Thus, depending on what type of normative/deontic sentences the putative method of deriving such sentences from factual ones is believed to be capable of generating, the trilemma will take slightly different forms. If, for instance, it is claimed that there exists a method of generating permissions departing from factual premises, then such a method would also (like a method generating obligations) justify many implausible moral norms. It is noteworthy that if we had a method which generates obligations and omissions (or prohibitions and omissions), then such a method, besides generating implausible norms, would generate logically contradictory moral norms.

7 Cf. J. Searle, How to Derive 'Ought' from 'Is', “The Philosophical Review” 1964/1, pp. 43-58.
} 
with the obvious exception of statement $1^{8}$. Let us also agree with Searle (unlike many of his critics) that there are no concealed evaluative premises in this argument, especially that a promise is not an evaluative concept ${ }^{9}$. On these two assumptions, the argument performs its task: it does demonstrate that the derivation of "ought" from "is" is possible. However, the philosophical significance of this derivation is not clear.

The point I wish to make is that if we interpret this derivation as related to justification in ethics, then we encounter the trilemma, that is: the derivation would be unsuccessful in its "justification" part for one of the three reasons being the parts of the trilemma described in the preceding section. Before I move on to showing the way in which Searle's method encounters the trilemma, I would like to emphasize two points. Firstly, as we will see, Searle's method does not fit in perfectly with the general description of the conditions of the trilemma presented above, because he does not claim that from any statement of fact an ought-statement can be derived, but only from some types of them, viz. those describing promises and analogous institutional facts. Secondly, the ought-statements derived using Searle's method are not general norms but individual ones. But, in spite of this, Searle's method does encounter the trilemma (as will be shown presently). This may attest to the fact that the conditions of the trilemma may have been formulated too restrictively, that is, as unnecessarily narrowing down the trilemma's scope to the methods that purport to derive general ought-statements for any human action. However, it would be rather difficult, given the paucity of the examples of the proposed methods of derivation of "ought' from "is", to formulate fully adequate conditions of the trilemma. Let me now show how Searle's method runs into this trilemma.

\subsubsection{Part 1 of the trilemma: The derivation would justify implausible moral norms}

If we take as the first premise the statement "Jones uttered the words «I hereby promise you, Smith, that I shall kill your enemy, Williams»", then we can proceed, along the argumentative path pointed at by Searle, towards the conclusion that Jones ought to kill Williams. In a likewise manner we can derive any kind of immoral duty (of cheating, stealing, etc.) of person $A$ from the statement describing the fact that $A$ uttered the words amounting to a promise to do an immoral act (that is, made an appropriate speech act constituting a promise).

\subsubsection{Part 2 of the trilemma: Or the derivation would presuppose a moral norm not derivable from facts}

If we want to "block" the derivation of immoral norms by excluding those promises which are immoral, we have to appeal to an external moral norm, that is, one not derivable from facts, which would enable us to distinguish those promises which justify

\footnotetext{
For an overview of various critical arguments raised against Searle's derivation, see, e.g., G.H. von Wright, Is and ought, in: E. Bulygin et al. (eds.), Man, Law and Modern Forms of Life, Dordrecht 1985, pp. 263-281.

9 I shall not analyze this point, but I would like to add that it is fairly controversial, even on Searle's own formulations. He wrote that in making "moves from (2) to (5) we rely on definitional connections between «promise», «obligate», and «ought»" (J. Searle, How to Derive..., p. 49), which might suggest that, given these definitional connections, the notion of "ought" is a part of the concept of "promise", and that, as a result, "promise" is an evaluative concept. One should also notice that, arguably, the "definitional connections" about which Searle writes, extend also to premise 1 , which contains the word "promise" (or, more precisely, the statement that the performative act of promise has been made). These polemical remarks notwithstanding, I assume in the course of my analysis, that "promise" is not an evaluative concept, and that Searle's derivation is indeed a derivation of "ought" from "is".
} 
"ought-statements" from those which do not. Strictly speaking, such a norm would "block" not only the transition to the "Ought-statement" (statement 5 in Searle's series of statements) but already the transition to statement 3 (about Jones placing himself under an obligation), or even to statement 2 (about making a promise). One may claim that Searle introduces such a norm (or a set of norms) in a concealed manner by introducing a ceteris paribus clause in his argumentation for the plausibility of transitions to the successive statements in his series: he argues that, for instance, the derivation of statement 5 from statement 4 is legitimate if "other things are equal", that is, if there do not exist any further considerations which would override the obligation to keep a promise. But this interpretation of Searle's ceteris paribus clause may not be true to his intentions; it seems that the main reason why he invokes it is to allow for the fact than obligations derived by his method may be only prima facie, and thereby may be overridden by other - stronger - obligations, not that they are not real obligations; as he wrote: "the fact that obligations can be overridden does not show that there were no obligations in the first place. On the contrary. And these original obligations are all that is needed to make the proof work" ${ }^{10}$. But if it is so, then Searle's derivation, if interpreted as having a justificatory goal, collapses already on the first part of the trilemma, since it may justify implausible moral norms; the fact that they are interpreted as only prima facie, not absolute, obligations, is inessential here. In short, in my view, these implausible obligations are simply not real, rather than real but only prime facie (capable of being overridden by other obligations).

\subsubsection{Part 3 of the trilemma: Why a non-moral criterion should be morally relevant?}

One could argue that Searle does not deal with the parts 1 and 2 of the trilemma because he believes that some words have deontological dimension encoded in their meanings, whereas others do not. But, in believing so, he runs into the third part of the trilemma, that is, he does not explain why a semantic (ergo non-moral) criterion should be morally relevant, that is, considered as providing grounds for the distinction between justified and non-justified moral norms.

\subsection{Interpretation}

The above critical analysis of Searle's derivation should be properly understood: its thrust is directed not at the derivation as such, but at such interpretation whereby the derivation constitutes a justification of the derived "ought-statement". It must be admitted, however, that if the above critical analysis is correct, it may also undermine the claim that the derived "ought-sentence" (statement 5) is a genuine moral "ought-sentence". Searle is certainly right in saying that it is not a hypothetical imperative in Kant's sense, which makes the duty - "ought" - conditional on the agent's willingness to achieve a certain goal. But, arguably, it cannot also be regarded, contrary to Searle's claim" ${ }^{11}$, as a "categorical imperative" without appealing (and thereby collapsing on horn 1 of the trilemma) to some external moral norm in order to decide whether the promise was a moral one.

\footnotetext{
10 J. Searle, How to Derive..., p. 50.

11 Cf. J. Searle, How to Derive..., p. 44.
} 
It may be worth adding that his derivation could not be regarded as providing a moral justification also for another reason, namely that one can easily apply his method of derivation of "ought" from "is" also to immoral legal "ought-" or "permission-sentences". Assume, for instance, that statement 1 is: "The Polish Parliament adopted, in a proper procedure, the law ordering the expropriation of all Polish citizens older than 75". Arguably, what follows from this statement (according to Searle's method) is "oughtstatement" 2: "All Polish citizens older than 75 ought to be expropriated". Or assume that statement 1 is: "The Polish Parliament adopted, in a proper procedure, the law vesting each Polish citizen with the right to kill with impunity one, but no more than one, other Polish citizen". Arguably, what follows from this statement (according to Searle's method) is "permission-statement" 2: "Each Polish citizen may (is permitted) to kill with impunity one, but no more than one, other Polish citizen". These derivations in the Searlian style have three features. The first one, already mentioned, is that they may be seen as justifying "ought-sentences" which, according to common moral intuitions, should not be regarded as justified. The second one is that they cannot distinguish between legal "ought" and moral "ought", and thereby cannot be regarded as a method of moral justification. The distinction between legal "ought" and moral "ought" is controversial, but at least in some contexts it is indispensable; for instance, one cannot formulate the legal-positivistic position without assuming the difference between these two types of "ought" (in ius-naturalism, by contrast, the distinction is blurred, with legal "ought" being at least partly reduced to moral "ought"; i.e. a norm can be endowed with legal "ought" only if it does satisfy the requirements of moral "ought"). The third one is that they also enable deriving another type of deontic statements, viz. "permissionstatements" (including immoral ones).

One way of avoiding the critique based on the idea of the trilemma is to consider Searle's derivation as not related to justifying moral norms. Indeed, Searle seems to have interpreted his derivation precisely in this way: not as related to the justification of "ought-sentences", but, rather, as related to the questions of social ontology. It is not accidental that it is in the context of his derivation of "ought" from "is" that Searle proposed the concepts of institutional facts and constitutive rules. Promises, obligations or rights which may constitute the basis for the derivation of "ought-sentences" are a specific category of facts, viz. institutional facts, distinct from brute facts ${ }^{12}$. The institutional facts presuppose the existence of institutions which are created by constitutive rules (or, more precisely, by systems of such rules). These rules provide that, in certain circumstances, a certain fact $X$ (e.g. uttering words, making gestures) should count as $Y$ (e.g. promise, marriage, obligation). Searle distinguished these rules from

12 The concept of brute facts was introduced by Gertrude E. Anscombe (G.E.M. Anscombe, On Brute Facts, "Analysis" 1958/3, pp. 69-72) and developed by John Searle into the distinction between brute and institutional facts. It is interesting to note that Searle's derivation of "ought" from "is" was, to some extent, anticipated by Anscombe, who argued that "it would be ludicrous to pretend that there can be no such thing as a transition from, e.g. «is» to «owes»" (G.E.M. Anscombe, Modern Moral Philosophy, "Philosophy" 1958/33, p. 3); she illustrated this thought by the following example: from the brute fact "I ordered potatoes, you supplied them, and you sent me a bill", one may derive the statement that "I owe you money". One more point should be mentioned. In his classic paper How to Derive... Searle operates only on the distinction between brute (noninstitutional) and institutional facts and writes explicitly that all promises, obligations or rights belong to the latter category. But in his later works (e.g. in The Construction of Social Reality, Berkeley 1995) he introduces another category: social facts (basically, referring to common actions based on collective intentionality) and he treats institutional facts as their subset. In my analysis, I discount this complication of Searle's theory. But it should be remembered that what he initially subsumed under the general category of brute facts may (on his later account) be social facts. 
regulative rules: "regulative rules regulate activities whose existence is independent of the rules; constitutive rules constitute (and also regulate) forms of activity whose existence is logically dependent on the rules"13. A question arises how the distinction between brute and institutional facts is related to the controversy over the relations between "ought-statements" and "is-statements". In response to this question one should note that once the concept of institutional facts is taken into account, it turns out that the category of "is-statements" is internally much more variegated than was previously believed: it embraces not only statements describing brute facts, but also statements describing institutional facts. The classification of factual statements presented in section 2 must therefore be supplemented: factual statements include also statements describing institutional facts. As Searle has convincingly demonstrated, from the former type of statements one can make a valid derivation of "ought-statements", though, as I have endeavoured to demonstrate, this derivation cannot be interpreted as a moral justification. Briefly speaking, the main merit of Searle's derivation lies in that it clearly shows the existence of a different type of facts, that is, institutional facts, ignored or rather not recognized by the philosophers who tackled the problem of relations between "oughtstatements" and "is-statements" before Searle.

Let me supplement the above analysis with one further reflection. The putative derivation of "ought" from "is" gives rise to the question whether an "ought-statement", by virtue of the fact that it was derived from an "is-statement" endowed with a truth-value, inherits, so to speak, the "is-statement's" truth-value. In other words, the question arises whether the derivation of "ought" from "is" commits one to the cognitivist metaethical position. Now, if the derivation of "ought" from "is" with a justificatory goal were successful, it would indeed be apt to assign the value of truth to the derived "ought-statement" and interpret this value in a cognitivist sense, that is, as a moral truth: a true moral norm providing an objective reason for action. But, as I have argued, a derivation cannot provide a moral justification. Accordingly, the assignment of truth-values to the "ought-statement" in Searle's derivation must have a different sense: it implies that it is true that Jones made a promise (and thereby ought to keep it, given the meaning of this institution); not that the derived "ought-statement" is morally justified (because, as I have argued, Searle's method enables one to justify also immoral "ought-statements"). Or, to put it differently, if Jones is to pay Smith five dollars, it is not because the "ought-statement" which formulates such an obligation has been derived from an "is-statement". Statement 5 - that Jones ought to pay Smith five dollars - may be a genuine "ought-statement", yet if it is such a statement, it is not by virtue of the derivation provided by Searle, but, for instance, because it is a concretization of a more general norm according to which promises to undertake morally acceptable actions ought to be, ceteris paribus, observed. It must be stressed that Searle's view on this point is not fully clear. It seems that in his paper from 1964 he rejected cognitivism, i.e. denied that moral norms may have truth-values, and thereby did not emphasize the ethical dimension of his derivation. This would be consistent with my interpretation of his derivation as not related to the problem of justification in ethics.

\footnotetext{
13 J. Searle, How to Derive..., p. 55. Even though the definitions of constitutive and regulative rules are clear, it may not always be easy to ascertain whether a given rule is constitutive or regulative. For instance, it might seem that the rules "one ought not to steal" or "one ought not to tell lies" are regulative because they appear to regulate pre-existing behaviour (as opposed, e.g. to the rules of chess which create the possibility of chess movements), but, rather surprisingly, Searle considers them to be constitutive rules, respectively: of the institution of private property and of the institution of making assertions (c.f. J. Searle, How to Derive..., p. 57).
} 


\section{Closing remarks on the problem of justification in ethics}

As far as the problem of justification in ethics is concerned, the results of the analyses pursued in this paper are mainly negative: I have argued that (1) the normative justification is incomplete; (2) the factual justification based on value-laden factual statements is either exposed to the problem of deriving "ought" from "good" or (assuming the definitional link between "ought" and "good") to the problem of resolving the controversies as to which facts are truly "good"; and (3) the factual justification based on value-free factual statements is impossible because it faces the trilemma. This negative result may lead to one of the two following conclusions: that there is something deeply mistaken in the very idea of complete ethical justification, that in seeking such a justification we commit "the mistake of supposing the possibility of proving what can only be apprehended directly by an act of moral thinking"14; or, less radically and more plausibly, that there may be something wrong in the very idea of ethical justification as usually conceived, i.e. as aimed at justifying moral norms in isolation from stronger metaphysical assumptions. As for the last point, Gertrude E. Anscombe may have been right in claiming that:

it is not possible to have such a conception [i.e. law conception of ethics, based on the notion of "moral ought" - W.Z.] unless you believe in God as a law-giver (...). But if such a conception is dominant for many centuries, and then is given up, it is a natural result that the concepts of "obligation", of being bound or required as by a law, should remain though they have lost their root (...) It is as if the notion "criminal" were to remain when criminal law and criminal courts had been abolished and forgotten (...) Hume discovered the situation which the notion "obligation" survived, and the notion "ought" was invested with that peculiar for having which it is said to be used in a "moral" sense, but in which the belief in divine law had long since been abandoned ${ }^{15}$.

She develops this thought in the following way:

It would be most reasonable to drop it [the notion of "moral ought" - W.Z.]. It has no reasonable sense outside a law conception of ethics [...] and you can do ethics without it, as is shown by the example of Aristotle. It would be a great improvement if, instead of "morally wrong", one always named a genus such as "untruthful", "unchaste", "unjust". We should no longer ask whether doing something was "wrong", passing directly from some description of an action to this notion; we should ask whether, e.g., it was unjust; and the answer would sometimes be clear at once ${ }^{16}$.

Anscombe's argument seems to be that we cannot avoid the following choice: either we retain the notion of moral norm ("moral ought"), but then we should, for the sake of coherence, assume the divine law conception of ethics, or we abandon this conception of ethics, but then we must also abandon the notion of moral norm (moral "ought") and replace it with some other concept (e.g. moral virtue, implying the use of "thick" moral concepts). It might seem, given the above quote, that Anscombe advocated the second part of the alternative (virtue ethics), but a closer reading of her paper, especially of those parts of it where she writes with unconcealed sympathy about deontological ethics (which formulates absolute prohibitions, that is, forbids certain things, e.g. killing

14 H.A. Prichard, Does Moral Philosophy Rest on a Mistake?, "Mind" 1912/21, p. 36.

15 G.E.M. Anscombe, Modern Moral..., p. 5.

16 G.E.M. Anscombe, Modern Moral..., p. 7. 
the innocent, treachery, vicarious punishment, adultery, no matter what consequences) and is critical towards the concept of "human flourishing" (characteristic for virtue ethics) that she endorses the divine law conception of ethics. Let us, then, examine this conception a little.

It is noticeable that there are two main ways of justifying moral "ought". One may define moral norms as divine commands: "action $a$ is right" would mean on this account "action $a$ is prescribed by God". However, this way of justifying moral "ought" gives rise to the objection that moral norms defined as divine commands are arbitrary: it remains unclear why a moral norm, just because it was commanded by God, should be regarded a reason for action. A more promising way of justifying moral "ought" does not appeal to God's commands, but to God's goodness/love and omniscience. If God is good/loving and omniscient, then He will accurately recognize right moral norms (which, nonetheless, are right irrespective of whether they are recognized by God or not). This second way of justifying "moral norms" enables overcoming the sceptical doubt according to which, given the frailty of human cognitive powers, we can never be certain that moral norms accepted by us are right/correct ones. Arguably, this kind of divine law ethics was accepted, at least hypothetically, by Leszek Kołakowski, who maintained, in the spirit of Dostoyevski's claim "if there is no God, then everything is permitted", that there can be no ethical absolute without the ontological Absolute ${ }^{17}$. What Kolakowski meant by this is that there can be no complete justification of moral norms without assuming the existence of God. His argument has had an epistemic character: God's command does not make a command a right moral norm, but is a criterion of right moral norms. Thus, Kołakowski rejected this variant of the divine law conception of ethics which assumes that "action $a$ is right" means "action $a$ is prescribed by God"18.

It might seem that the two variants of divine law conception of ethics sketched above fall on the different sides of the dilemma of divine ethics formulated by Plato in his dialogue titled Eutyphro: either something is good because it was ordered by God or it was ordered by God because it is good. If the former, moral norms prove to be arbitrary; if the latter, appealing to God's commands is redundant. However, apparently, the second variant of divine law conception of ethics evades the dilemma, as it does not identify moral norms with God's commands and clearly explains why appealing to God's commands is necessary: without God's issuing commands (God whom we assume to be good without knowing beforehand the substance of moral rules) we would be uncertain whether the moral norms we follow are genuine moral norms. One may still ask, however, in what sense the fact that moral norms are recognized by God may provide their justification. The plausible answer seems to be that this justification is epistemic: moral norms do not derive their normative (moral) "force" from the fact that they are recognized by God; they derive this kind of force from "themselves" (or from higherlevel moral norms) but the fact they have been recognized by God resolves the problem of our epistemic uncertainty of whether the given norms are really moral ones. That

17 Cf. L. Kołakowski, Jeśli Boga nie ma... O Bogu, Diable, Grzechu i innych zmartwieniach tak zwanej filozofii religii [Eng. If There Is No God... On God, the Devil, Sin, and Other Worries of the So-Called Philosophy of Religion], London 1987.

18 It should also be stressed that Kołakowski did not explicitly endorse this kind of divine law ethics (hence his argument is hypothetical): he argued that if we do not assume the existence of God, then we cannot speak about the existence of knowable, absolute moral norms (even if they exist, we cannot be sure that we know them). The exegesis of the sense which Dostoyevsky gave to his famous sentence quoted above would be more complicated; it cannot be excluded that Dostoyevsky would be inclined to accept the more radical variant of divine law ethics according to which an action assumes a moral character by virtue of the fact that it was commanded by God. 
a norm is self-evident for a human being cannot count as its justification; but a norm can be regarded as justified if it is self-evident for a good/loving and omniscient God.

It should be added that the theistic framework seems to be necessary also for a complete justification of virtue ethics. The basic tenet of virtue ethics is the assumption about the existence of "natural ends", including the "natural end" (telos) of human being, that is: a vision of human flourishing. Accordingly, acting morally (i.e. virtuously) serves the realization of a human telos. Thus, moral virtues acquire a quasi-instrumental justification: they are to be practised because by practising them we can flourish as human beings. However, we may not be sure what telos is; the uncertainty that arose within "law ethics" can therefore appear also within "virtue ethics". The problem of the (epistemic) justification of virtue ethics disappears, however, if we assume that telos can be recognized by God. Clearly, it is not God himself that confers normative/moral "force" on virtues - it is telos itself that performs this task - but God's existence (and God's knowledge) provides an (epistemic) justification of our knowledge of telos (it removes the possibility that we may be wrong in identifying its content). Thus, complete justification of moral recommendations becomes possible only if we place virtue ethics in the theistic framework, that is, the justification becomes possible only within virtuetheistic ethics or, to use an awkward but more precise term, teleological-theistic ethics (it is noticeable that the two variants of deontological-theistic ethics discussed above have their counterparts in teleological-theistic ethics).

Let me summarize. Alisdair MacIntyre seems to have been right when he wrote that the very problem of the derivation of "ought" from "is" appeared (for the first time with full clarity and force in Hume's reflection) as a result of the fall of the so-called classical picture of the world - the picture based on the assumption of the existence of "natural ends" and of God ${ }^{19}$. But he does not seem to properly identify the element of this picture which is crucial for the moral justification. In his view, the element is the "teleological scheme", that is, the ideas of natural ends (telē). It seems more apt to maintain, however, that the crucial element is the assumption of the existence of God: it is precisely this assumption, not the assumption about the existence of "natural ends", which ultimately provides moral justification within both types of theistic ethics - deontological and teleological.

\title{
Why Moral Norms Cannot be Reduced to Facts: On a Trilemma in Derivations of "Moral Ought" from "Is"
}

\begin{abstract}
The paper aims at formulating a certain trilemma that applies to justifying moral norms. The trilemma can be succinctly stated as follows: any attempt to derive a "moral-oughtstatement" from an "is-statement" with a justificatory goal (i.e. to justify the "moral-oughtstatement"), even if it were successful in its "derivation" part (i.e. logically correct), would be unsuccessful in its "justificatory" part for one of the following three reasons: (1) it would consider each human action of which a factual statement can be made as morally obligatory, thus "justifying" a large number of implausible moral norms; or (2) it would presuppose a moral norm not derivable from facts; or (3) it would not explain why the distinction - made based on extra-moral criteria - between those factual statements about human actions from which moral norms can be derived and those from which they cannot be derived should count as
\end{abstract}

19 A. MacIntyre, After Virtue. A Study in Moral Theory, Notre Dame (Indiana) 1981. 
morally relevant. The trilemma is illustrated in the paper by an analysis of Searle's well-known attempt at deriving "ought" from "is". Some further implications of the trilemma regarding the proper way of justifying moral norms are also examined.

Keywords: ought-statements, is-statements, logical derivation, ethical justification, Searle, Anscombe, naturalistic ethics, divine ethics 


\section{BIBLIOGRAFIA / REFERENCES:}

Anscombe, G.E.M. (1958). On Brute Facts. Analysis 18/3, 69-72.

Anscombe, G.E.M. (1958). Modern Moral Philosophy. Philosophy 33/124, 1-19.

Kołakowski, L. (1987). Jeśli Boga nie... O Bogu, Diable, Grzechu i innych zmartwieniach tak zwanej filozofii religii. London: Aneks.

MacIntyre, A. (1981). After Virtue. A Study in Moral Theory. Notre Dame (Ind.): University of Notre Dame Press.

Prichard, H.A. (1912). Does Moral Philosophy Rest on a Mistake? Mind 21/81, 21-37.

Searle, J.R. (1964). How to Derive 'Ought' from 'Is'. The Philosophical Review 73/1, 43-58.

von Wright, G.H. (1985). Is and ought. In E. Bulygin, J.-L. Gardies, I. Niiniluoto (Eds.), Man, Law and Modern Forms of Life. Dordrecht-Boton: D. Reidel. 